\title{
$\begin{array}{ll}\text { Research Square } & \text { Preprints are preliminary reports that have not undergone peer review. } \\ \text { They should not be considered conclusive, used to inform clinical practice, }\end{array}$ or referenced by the media as validated information. \\ Twin Deliveries: The Prevalence and Perinatal Outcomes in Public Hospitals in Dar es Salaam City, Tanzania
}

\section{Zavery Benela}

Mbeya Referral Hospital

Alfred Chibwae ( $\square$ achibwae@gmail.com )

CUHAS BUGANDO https://orcid.org/0000-0002-8982-4086

Ola Jahanpour

Kilimanjaro Christian Medical University College

Dismas Matovelo

Catholic University of Health and Allied Sciences

\section{Research article}

Keywords: Twin Pregnancy, Perinatal outcomes, Tanzania

Posted Date: December 3rd, 2019

DOI: https://doi.org/10.21203/rs.2.17959/v1

License: (c) (1) This work is licensed under a Creative Commons Attribution 4.0 International License. Read Full License 


\section{Abstract}

Background The perinatal mortality rates are five times higher in twin pregnancies than singleton pregnancies, therefore antenatal management and safe delivery of twin pregnancies are important issues in obstetrics. This study aimed at providing data on the proportion of twin deliveries in four public hospitals in Dar es Salaam and an insight on the fetal outcomes in relation to their modes of delivery.

Methods This was a cross sectional study in which all women who delivered twin babies were interviewed and medical records on their delivery summary were obtained in the labour and post-natal wards in four public hospitals in Dar es Salaam between July and December 2011. Post-natal follow up was done on seventh day by contacting women by telephone to establish the neonatal status.

Results There were 33,638 total deliveries of which 672 were twin deliveries making the prevalence of $2.0 \%$ (20 per 1,000 births). Of all twin deliveries analyzed (666 pairs), 373(56.0\%) had the diagnosis of twin pregnancy made antenatally. Vaginal delivery was the major mode of delivery $(77.3 \%)$. whereas combined delivery in which the first twin was delivered vaginally and the second twin by caesarian section accounted for only $2.6 \%$. At birth $1252(94 \%)$ of twins were alive, $60(4.5 \%)$, were fresh stillbirths and $20(1.5 \%)$ were macerated stillbirths. Low Apgar score was more to first twins delivered vaginally compared to first twins ( $p$-value=0.003). Low Apgar score (AS $<7$ ) was more amongst second twins delivered vaginally at 30 minutes or longer $27(48.2 \%)$ compared to twins delivered in less than 30 minutes $72(15.4 \%)$, (pvalue $=0.001)$.

Conclusion There was a significant association between vaginal delivery and low Apgar score at one minute. Long duration of twin to twin delivery interval was associated with low Apgar score of the second twins delivered vaginally. Perinatal mortality rate was also higher in the second twins compared to the first twins. The time delivery interval of the second twin should be made as short as possible by active management of all second twins. Neonatal facilities are required in all hospitals conducting twin deliveries to care for premature babies.

\section{Background}

The phenomenon of twinning has fascinated mankind throughout its recorded history. Twins have often been regarded as being inherently different from singletons, and societal responses to their birth have ranged from awe to fear [1]. Twin fetuses commonly result from fertilization of two separate ova and are termed as double ovum, dizygotic or fraternal twins. About a third as often, twins arise from a single fertilized ovum that subsequently divides into two similar structures, each with the potential for developing into a separate individual. These twins are termed as single-ovum, monozygotic, or identical twin (2). All dizygotic twins and one-third of monozygotic twins have separate inner and outer sacs and are thus dichorionic-diamniotic. Two thirds of monozygotic twins have a single outer sac and two inner sacs (monochorionic diamniotic) and about $1 \%$ of twins will share their inner sac (monochorionicmonoamniotic) [2]. 
In monozygotic twins, various types of chorionicity and amnionicity can occur as result of when the fertilized oocyte divides. Division occurring between the first day and third day results into dichorionicdiamniotic twins accounting for about $1 / 3$ of cases. Division between the fourth day and the eight-day results into monochorionic-diamniotic twins (about 2/3 of the cases). Division occurring late between ninth and thirteenth day after fertilization results into monochorionic monoamniotic (about 1\%). Division taking place beyond the thirteenth day results into conjoined twins[2].

The incidence of twin pregnancies has increased remarkably since the late seventies because of the improved reproductive medicine and a greater proportion of older pregnant mothers who naturally have a higher incidence of multiple gestations[3-6]. The occurrence and frequency of twinning varies across human populations[7]. The maternal age, socio-environmental factors, increase in the use of contraceptives, the race of human population, increase in spontaneous abortion rate and seasonal variations, are among the factors that could influence twinning rate[7].

Twin pregnancies are more prone to complications than single pregnancies. Early in pregnancy there is high risk of miscarriage and sometimes one fetus dies and is reabsorbed resulting into the vanishing twin syndrome[8]. Other complications associated with twin pregnancy include high incidence of hypertension (pregnancy-induced hypertension, pre-eclampsia or eclampsia), gestational diabetes mellitus, bleeding in pregnancy (placenta praevia or abruptio), preterm birth and small-for-gestational-age babies due Intrauterine growth restriction (IUGR), postpartum hemorrhage, congenital malformations, and Twin to twin transfusion syndrome (TTTS)[2, 9].

Twin pregnancies in general population comprise about $1 \%$ of all pregnancies, but can account for up to $10 \%$ of perinatal mortality [4]. Low birth weight and prematurity are the main causes of high perinatal morbidity and mortality in twins, whereas malpresentation and the hazards of delivery are next in order of concern. For these reasons, twin pregnancy is considered a high-risk pregnancy; different aspects of the risk include the mode of delivery, which remains a subject of a controversy and discussion among obstetricians. Because the perinatal mortality rates are 3-6 times higher in twin pregnancies than singleton pregnancies, antenatal management and safe delivery of twin pregnancies are important issues in obstetrics $[10,11]$. There were no study that focused on multiple pregnancies and their fetal outcome. So this study, aimed at determining the prevalence, mode of delivery and fetal outcome of twin deliveries in four public hospitals in Dar es Salaam.

\section{Methods}

\section{Study area and design}

This was a descriptive cross-sectional study conducted in four public hospitals in Dar es Salaam City from 1st July to 31st December 2011 which provided maternal and child health services. These hospitals were Muhimbili National Hospital (MNH), which is a tertiary and University teaching hospital, and three municipal hospitals namely Amana hospital (Ilala Municipality), Mwananyamala hospital (Kinondoni municipality), and Temeke hospital (Temeke municipality). 
$\mathrm{MNH}$ had an average of 20 to 30 deliveries per day and about 8 to 12 operative deliveries in which both emergencies and elective are performed each day. The average number of multiple gestations delivered per month is $20-30$. Temeke hospital had an average of 40 and 60 deliveries per day, out of which $2-4$ are caesarian sections. The average number of multiple gestations delivered per month was 30-40. Mwananyamala hospital had an average of 35-45 deliveries per day with $4-6$ caesarian sections. The average number of multiple gestations delivered per month were 15-25. Amana hospital had 40-60 on average number of deliveries per day in which 3-5 of them were caesarian sections. The average multiple gestations delivered per month were 15-20.

All women admitted in labour wards or post-natal wards already delivered and their newborns/ infants were included in our study from 1st July to 31st December 2011.

\section{Data collection}

A structured closed ended English questionnaire translated into Swahili language was used for data collection. Data was collected by four oriented research assistants (Nursing officers), one in each hospital. At $\mathrm{MNH}$, the principal investigator collected the data when the assistant was absent. Pretesting of the questionnaire was done with assistant to ensure reliability. Data was collected daily from women who had delivered twin babies whilst in labour ward or post-natal wards after all the management to the mother and newborns have been given according to the existing respective hospital protocols. Explanation about the study and informed written consent to participate was obtained. Counseling was done to all women who had either still birth or early neonatal death before continuing with interview.

Information was also obtained from the patient's medical record or antenatal clinic card on the delivery summary which included the time of delivery, sex, birth weight, and Apgar score of the babies. In the case of caesarean delivery, the indications and whether this was done as an emergency or elective was counter checked in the records. Gestation age in weeks at the time of delivery was estimated by calculation from the last normal menstrual period (LMP), or an early antenatal ultrasound done was used.

For the purpose of not missing a client, the delivery registers were used to counter check the deliveries of each day. The principal investigator also kept track of the neonates especially those who were admitted in the neonatal unit at $\mathrm{MNH}$ and communicated with research assistants about the referred neonates. Each woman was asked for their cell phone numbers for the purposes of knowing the condition of the babies at day seven if discharged, for mothers with no cell phones, the cell phone number of their spouses/partner or housemate relative was taken and used for contacting them. Reasons for admission for neonates was obtained from the file as recorded by the attending doctors.

\section{Data analysis Procedure}

Data collected was entered into EpiData software and data cleaning was done. Data was analyzed using the Stata version 10. Frequency and distribution tables to show the number of twin deliveries out of total deliveries in each hospital, mode of delivery for the first and second twin were described. The association 
between neonatal outcome and the mode of delivery and inter-twin interval for vaginal delivery were determined using the Chi square. P-value less than 0.05 were taken as statistically significant.

\section{Ethical Consideration:}

The study was approved by the Research and Publication Committee of Muhimbili University of Health and Allied Sciences (MUHAS). Permissions to conduct the study were obtained from MNH Director and Municipal Medical Officers of Health from Temeke, Ilala and Kinondoni municipals and from the Medical Officer In charge of their respective hospitals.

Women meeting the inclusion criteria were given explanation about the aim of the study, its benefits and were reassured that there were no risks associated with participating in the study. All the information obtained was confidential and used for the study only. A voluntary informed consent was obtained from each participant before starting the interview. Women who had perinatal death were counseled by the PI or research assistants as all were senior health staff trained in patient counselling.

\section{Results}

Demographic characteristics of the studied population in the four hospitals

Majority $507(76.1 \%)$ of the women in this study were aged between $20-34$ and the median age was 28 years with a range of $16-46$ years. Of the studied women, $587(88.1 \%)$ were either married or cohabiting and only $11.4 \%$ were single. Secondary education level was common accounting for $50.6 \%$ followed primary education $32.7 \%$. At the time of delivery $46.7 \%$ of the studied women had an estimated gestation age of less than 37 weeks and the mean gestation age at the time of delivery was $36.2 \pm 3.2$ weeks as shown in table 1.

\section{Prevalence of twin deliveries in the four hospitals}

There was a total of 33,638 deliveries in the four hospitals during the six months period (July-December 2011) covered by this study. Of the 33,638 deliveries, $672(2.0 \%)$ were twin deliveries. Out of the 666 twin deliveries, 373(56.0\%) the diagnosis of twin babies was made during ANC. Of these diagnoses, 30(8\%) were made only clinically, $176(47.2 \%)$ using obstetric ultrasound and $167(44.8 \%)$ the diagnosis was made by both clinical judgment and the use of an ultrasound. The proportion of twin deliveries in each hospital was as follows; Muhimbili National Hospital had a total of 4813 deliveries with 195(4.1\%) twin deliveries, Temeke hospital had a total of 10429 deliveries with 228(2.2\%) twin deliveries, Mwananyamala hospital had a total of 7490 deliveries with 132(1.8\%) twin deliveries and Amana hospital had a total of 10,906 deliveries with $117(1.1 \%)$ twin deliveries. A total of 666 twin deliveries, resulting in the delivery of 1,332 twin babies fulfilled the study inclusion criteria. Five pairs had a gestation age of less than 28 weeks and one pair had a gross congenital malformation (anencephaly) and was therefore excluded in the analysis. 
Majority $515(77.3 \%)$ of the twin pregnancies were delivered vaginally, $134(20.1 \%)$ delivered by caesarian section while $17(2.6 \%)$ had a combined delivery that is the first twin was delivered vaginally and the second by caesarian section. Three quarters $(76.2 \%)$ of all caesarian sections were done under emergency as compared to $23.8 \%$ which were planned. Muhimbili National Hospital had almost a 1:1 ratio between vaginal delivery and caesarian section as shown in table 2.

\section{Neonatal outcome at birth according to the mode of delivery}

At the time of delivery out of the 1,332 twins, 1252 (94\%) were alive and $60(4.5 \%)$ were fresh stillbirths (FSB) and 20(1.5\%) were macerated stillbirths (MSB0 as shown in table 3a. Low Apgar score was more to first twins $76(14.5 \%)$ delivered vaginally compared to first twins $5(3.5 \%)$ delivered by caesarian section and this difference was statistically significant ( $p$-value $=0.003$ ). Also, more second twins $116(22.2 \%)$ delivery vaginally had low Apgar score compared to second twins 11(7.7\%) delivered by caesarian section and this difference was statistically difference ( $p$-value $=0.001)$. There was no significant difference in fresh stillbirths, macerated stillbirths between first and second twins in the two modes of delivery as shown in table $3 b$.

\section{Time interval for vaginal delivery of second twins and their outcomes}

Low Apgar score (AS $<7$ ) was more amongst second twins delivered vaginally at 30 minutes or longer $27(48.2 \%)$ compared to twins delivered in less than 30 minutes $72(15.4 \%)$, and this was statistically significant both at one minute and five minutes ( $p$-value $<0.0001)$. There was no significant difference in stillbirths for second twins delivered vaginally in less than 30 minutes or more than 30 minutes ( $p$-value $=$ 0.44). Table 4 summarizes these results.

\section{Perinatal outcomes.}

On day seven after delivery neonates were followed up by contacting either the mother or the father with whom a cell phone number was taken during the initial interview. Of the 1,332 babies delivered, we managed to get the information of 1,216(91.3\%) babies out of which the first twins were $606(91.0 \%)$ and second twins were $610(91.6 \%)$. Those lost to follow up were not used in the calculation of the perinatal mortality rate $60(9.0 \%)$ first twins and $56(8.4 \%)$ second twins. The overall perinatal mortality of twins in the four hospitals was 155 per 1,000 births. Second twins (184 per 1,000 births) had higher perinatal mortality compared to the first twins (125 per 1,000 births) table 5. During the study period (July-December 2011) Muhimbili National Hospital had an overall perinatal mortality of 72 per 1000 births (Total deliveries 4813, stillbirths 320 and early neonatal deaths 25$)$

Different reasons accounted for neonatal admissions of the babies who were still in neonatal units on day seven after birth, 89(16.8\%) first twins and 93(18.7\%) second twins. There was more than one cause of admission in some of the babies however prematurity was the leading cause of admission of both first twins 51(48.6\%) and second twins 62(53.4\%) Table 6.

\section{Discussion}


The birthrate of monozygotic twins is constant worldwide (approximately 4 per 1000 births). Birth rates of dizygotic twins vary by race. The highest birth rate of dizygotic twinning occurs in African nations, and the lowest birth rate of dizygotic twinning occurs in Asia[13].

The prevalence of twin deliveries in the four public hospitals of Dar es Salaam was $2.0 \%$ equivalent to 20 per 1,000 births. These findings are comparable to a study done in two rural district hospitals in South Western Highlands of Tanzania where the prevalence ranged from 15 to 20 per 1,000 births [14].The similarities in these two studies is that, both were based on hospital data. However, the study populations were different as the present study in based on urban whose population's demographic characteristics might differ to rural population. This prevalence was lower compared to a study in Sumve district hospital, Kwimba in Mwanza which had prevalence of 39 per 1000 births [15]. However, study done in Sumve compared perinatal outcomes and twinning rate between prospective community-based survey and hospital data [15]. MNH had the highest (4.1\%) rate of twin deliveries compared to municipal hospitals in this study. This may be because MNH being a tertiary hospital receive more twin pregnancies from the municipal hospitals as these are classified as high risk pregnancies during antenatal care and delivery.

The findings in this study also showed a low prevalence compared to those found in Western Africa where the twinning rate is said to be highest in the world. A study in Southwest Nigeria to assess the frequency of twinning in four hospitals had an overall average frequency of 40.2 per 1000 deliveries, and this ranks among the highest recorded rates of twin births in the world [7]. The difference in prevalence of twins between this study and those in West Africa may be due to differences in diet, maternal history of twinning and some socio-environmental factors which are said to influence the twinning rate. In developed countries the twinning rate is also high (2.7-2.8\%) compared to this study, several reports imply this to increased use of Assisted Reproductive Technology (ART) which has not been the case yet in developing countries[16].

The optimal safe mode of delivery of twins remains a challenge and a subject of controversy among obstetricians. In this study the major mode of delivery was vaginal delivery accounting for $77.3 \%$ of all twin deliveries compared to $20.1 \%$ delivered by caesarian section. The rate of caesarean section in this study is lower compared to other studies [17-20]. A study by Mutihir et al found the rate of caesarian section to be $41.3 \%$ in Nigeria [21]. Also, in some developed countries [22]the rate of caesarian section in twin delivery has been increasing. Some of factors which has correlated with the increase in the caesarean section rate include the decline in internal version and breech extraction of a second transverse lie twin[23]. In this study, the presentation of the first and second twins was not studied, which may have influenced the mode of delivery.

Among the caesarian delivery $76.2 \%$ were emergencies and $23.8 \%$ were planned. The delivery mode in majority of twins is decided by the clinician attending the patient during antenatal care, labour and delivery. However, few twins does their mode of delivery planned during the antenatal period. In this study, about two thirds of all twin delivered had their diagnosis made during the antenatal period, and approx. one fifth of them had their mode of delivery planned in the antenatal period. The American College of Obstetricians and Gynecologists (ACOG) suggests that the best route for the twin delivery should be based on the presentation of the fetuses, the ease of fetal heart rate monitoring, the maternal and fetal status[24] 
Common indications for caesarian section were prolonged or obstructed labour (16.9\%) and previous caesarian delivery (18.5\%). For those who had combined delivery, retained second twin accounted for $5.6 \%$ of all indications, other indications for combined delivery were transverse lie and cord prolapse.

Undiagnosed twins during the antenatal period and labour is common, this was reflected by $10(5.6 \%)$ indications for caesarian section which had a diagnosis of fetal pelvic disproportion (big babies) but intraoperatively it was found to carry a twin pregnancy. It's important to have the diagnosis of twin pregnancy during the antenatal period or before labour so that the mode of delivery is planned.

The modes of delivery at $\mathrm{MNH}$ were almost in ratio of 1:1 between vaginal and caesarian delivery. This may be explained by the fact that twin pregnancy is high risk gestation with many associated complications as in this study $46.7 \%$ of all twin pregnancy delivered at an estimated gestation age of less than 37 weeks (preterm delivery). With a risk of preterm delivery, municipal hospitals tend to refer these women to $\mathrm{MNH}$ for premature neonatal care. Also, twin pregnancy with previous caesarian delivery is likely to attend the antenatal clinic at tertiary hospital. There is no trial of labour in twin pregnancy with previous caesarian delivery leading to the high caesarian delivery at $\mathrm{MNH}$ compared to municipal hospitals.

In this study there were lower Apgar score at one minute in first twins delivered vaginally compared to first twins delivered by caesarian section and in second twins delivered vaginally compared to second twins delivered by caesarian section. These findings agree with a study by Ji Young at el done in Korea who found the difference in one-minute Apgar scores of more than 2 occurred more in twin gestations delivered vaginally, than in the cesarean delivery $(p=0.048)$. In the same study the difference in five minute Apgar scores of more than 1 showed a significantly higher incidence in the vaginal delivery group than in the cesarean delivery group $(p=0.038)[11]$. In this study there were no statistically significant difference in Apgar score observed at five minutes and stillbirths between the two modes of delivery.

In contrast to this study, a study by Dera et al in Poland showed a significant tendency towards low one minute Apgar score in the second twins delivered vaginally, but when the score was grouped to low $(<7)$ and normal $(\geq 7)$ Apgar score, the final data did not indicate any statistically significant differences between the two modes of delivery[4]. However, the study by Dera et al was a randomized study with either planned vaginal delivery group or planned caesarian section group which is not the case in the present study in which the mode of delivery in majority was not pre-planned and hence lower Apgar score in twins delivered vaginally.

Within twin pairs the second born twin is more prone to birth asphyxia, which is mostly related to delayed delivery. In this study fresh stillbirth and low Apgar score of the second twins delivered vaginally were significantly high both at one and five minutes when the inter twin delivery interval was 30 minutes or longer compared to those delivered in less than 30 minutes ( $p$-value $<0.0001$ ). These findings concur with literature that stress the risk associated with long duration of delivery of the second twin.Leung et al. observed that the risk of fetal distress and acidosis in the second twin are higher when twin-to-twin delivery interval is beyond 30 minutes[25]. Also a population based cohort study in Hesse Germany by Stein et al found that increasing time interval was related to a decline in the mean umbilical arterial $\mathrm{pH}$ and base excess, and fetal acidosis, Apgar score $<7$ after 1, 5 and 10 minutes[26]. Schmiz et al found the mean inter 
twin delivery interval of $4.9+/-3.2$ minutes after vaginal birth of the first twin. With this very short inter twin delivery time of the second twin the perinatal outcomes were not different according to the mode of delivery [27]. Adverse outcomes (apgar score $<7$ and fresh stillbirth) in second twins delivered vaginally in this study possibly reflect inadequate active management of the second twin or lack of proper selection criteria for right mode of delivery before or during labour. Therefore, it is important to shorten the inter twin delivery interval as the difference in the inter-twin delivery interval may be the most important factor to causing the inconsistent prognosis of the second twins.

Twin deliveries have a large impact on perinatal deaths. The perinatal mortality rate for the second twins (184per 1000 births) in this study was high compared to first twin (125per 1,000 births) with the overall perinatal mortality rate of 155 per 1000 births. Despite being high, this overall perinatal mortality rate was lower compared to a study by Kidanto et al at MNH which found a perinatal mortality of 269 per 1,000 births for multiple pregnancy (majority being twin pregnancy). Compared to this study, that by Kidanto et al was a retrospective analysis of the hospital data over five years which might be more reliable as in the present study some data was missing [12]. Also, the perinatal mortality in this study is high compared to another study in south western Tanzania where the perinatal mortality for twins was 57per 1000 births. Both the two studies were based on district hospital data [14]. Most prospective studies show low twins' perinatal mortality this is probably related to the prior antenatal diagnosis of all twins, careful intrapartum monitoring, planned mode of delivery and inclusion of uncomplicated pregnancies. The poor outcome for second twin (high perinatal mortality rate) in this study may be related to lack of early diagnosis and inadequate intrapartum management of the second twins. On day seven $89(16.8 \%)$ and $93(18.7 \%)$ of the first and second twins respectively were admitted in the neonatal units. Prematurity was the leading cause of admission for both first and second twins, this reflect the high proportion (46.7\%) of preterm delivery in this study.

Limitations of this study include the missing data on the neonatal status on the seventh day after delivery due to lack of contact or cell phones therefore this hinders the reliability of the perinatal mortality rates. This study provides data that indicate twin deliveries are common in these four public hospitals but being a hospital based study and limited to public hospitals, we cannot generalize these findings to represent the whole population of Dar es Salaam and Tanzania in general.

\section{Conclusions}

Twin deliveries in four public hospitals in Dar es Salaam contribute to about $2.0 \%$ of all deliveries, with $\mathrm{MNH}$ having the highest proportion. Majority are delivered vaginally; while for those who delivered by caesarian section, the surgery was largely done on emergency basis because of low proportional of antenatal diagnosis and planned mode of delivery. However, this study does not conclude the best mode of delivery for the twin pregnancy.

Long duration of twin to twin delivery interval is associated with adverse outcomes of the second twins delivered vaginally. Perinatal mortality rate was also higher in the second twins compared to the first twins. This is likely due to inadequate intrapartum management of the second twins. 
The time delivery interval of the second twin should be made as short as possible by active management of all second twins. Neonatal facilities are required in all hospitals conducting twin deliveries to care for premature babies.

\section{Abbreviations}

AS: Apgar score, ANC: Antenatal Clinic, ART: Assisted Reproductive Technology, CS: Caesarean Section, IPPM: Intramural Private Practice Muhimbili, IUGR: Intrauterine Growth Restriction, LWB: Low Birth Weight, MNH: Muhimbili National Hospital, MUHAS: Muhimbili University of Health and Allied Sciences, NPC: New Paediatrics Complex, PMR: Perinatal Mortality Rate, FSB: Fresh Stillbirth, MSB: Macerated Stillbirth, TTTS: Twin-Twin Transfusion Syndrome, VBAC: Vaginal Birth after Caesarean section, VLBW: Very Low Birth Weight, WHO: World Health Organization

\section{Declarations}

\section{Ethics approval and consent to participate}

The study was approved by the Research and Publication Committee of MUHAS. Permissions to conduct the study were obtained from MNH Director and Municipal Medical Officers of Health from Temeke, llala and Kinondoni municipals and from the Medical Officer In charge of their respective hospitals.

Women meeting the inclusion criteria were given explanation about the aim of the study, its benefits and were reassured that there were no risks associated with participating in the study. All the information obtained was confidential and used for the study only. A voluntary informed consent was obtained from each participant before starting the interview. Women who had perinatal death were counseled by the PI or research assistants as all were senior health staff trained in patient counselling.

\section{Consent for publication}

Not applicable.

\section{Competing interests}

\section{The authors declare that they have no competing interests.}

\section{Funding}

The study had no external funding. All operational costs were met by authors

\section{Availability of data and materials}


The datasets generated and analyzed during the current study are available from the corresponding author on reasonable request.

\section{Acknowledgements}

The authors acknowledge all those who participated in the preparation of this manuscript and those who were involved in the care of our study patients. Special thanks go to women and their twin babies who were involved in this study. Also, we acknowledge to nurses for their support during data collection.

\section{Authors' contributions}

ZB: Principal investigator, concept development, data collection, data analysis and interpretations; AC: Drafting of the manuscript, OJ and DM: manuscript development. All authors have read and approved the final version of this manuscript, including the authorship.

\section{References}

1.Gabbe, S. G., et al., Obstetrics: Normal and Problem Pregnancies E-Book. 2016: Elsevier Health Sciences.

2.Corsello, G. and E. Piro, The world of twins: an update. J Matern Fetal Neonatal Med, 2010. 23 Supp/ 3: p. $59-62$.

3.Roland Axt, D. M., Jochen Hendrik, Kulbilay Ertan, and a.W. S. Michaela von Blohn, Maternal and neonatal outcome of twin pregnancies complicated by single fetal death. J Perinat Med, 1999. 27(3): p. 221-7.

4.Anna Dera, G. H. B., Louis Keith, The mode of delivery in twin pregnancy Part I. Neonatal outcome. Archives of Perinatal Medicine 2008. 14(1): p. 7-22.

5.Corsello, G. and E. Piro, The world of twins: an update. The Journal of Maternal-Fetal \& Neonatal Medicine, 2010. 23(sup3): p. 59-62.

6.Axt, R., et al., Maternal and neonatal outcome of twin pregnancies complicated by single fetal death. Journal of perinatal medicine, 1999. 27(3): p. 221-227.

7.Akinboro, A., M. A. Azeez, and A. A. Bakare, Frequency of twinning in southwest Nigeria. Indian J Hum Genet, 2008. 14(2): p. 41-7.

8.Brick., G., Multiple birth versus single birth issues. The Australian and New Zealand Journal of Obstetrics and Gynecology, 2006. 46 (suppl)(1): p. 529-537.

9.Chan., P. F. Y., Obstetric Implications of multiple gestation. The Australian and New Zealand Journal of Obstetrics and Gynecology, 2006. 46(suppl.)(1): p. 11-13. 
10.Minakami, H. and I. Sato, Reestimating date of delivery in multifetal pregnancies. JAMA, 1996. 275(18): p. $1432-4$.

11.Kwon, J. Y., et al., Umbilical arterial blood gas and perinatal outcome in the second twin according to the planned mode of delivery. Int J Med Sci, 2011. 8(8): p. 643-8.

12.Kidanto, H. L., et al., Analysis of perinatal mortality at a teaching hospital in Dar es Salaam, Tanzania, 1999-2003. Afr J Reprod Health, 2006. 10(2): p. 72-80.

13.Fletcher GE, Z. T., Pramanik AR, Ford SP. and Multiple Births, Accessed through http://emedicine.medscape.com/article/977234-overview.

14.van Roosmalen, J., Multiple pregnancy as a risk factor in rural Tanzania. Trop Geogr Med, 1988. 40(3): p. $196-200$.

15.Walraven, G. E., et al., Comparison of perinatal outcome in rural Tanzania as obtained from a prospective community-based survey and hospital data. Trop Geogr Med, 1994. 46(1): p. 11-3.

16.WHO, Neonatal and perinatal mortality: country, regional and global estimates. 2006.

17.Muganyizi, P., et al., Caesarean section: trend and associated factors in Tanzania. African Journal of Midwifery and Women's Health, 2008. 2(2): p. 65-68.

18.Eleje, G., et al., The rate of Caesarean section in Nnewi, Nigeria: A 10-year Review. Afrimedic Journal, 2010. 1(1): p. 11-14.

19.Lyimo, F. M., et al., Single dose of gentamicin in combination with metronidazole versus multiple doses for prevention of post-caesarean infection at Bugando Medical Centre in Mwanza, Tanzania: a randomized, equivalence, controlled trial. BMC pregnancy and childbirth, 2013. 13(1): p. 123.

20.Mutihir, J. T., P. H. Daru, and I. A. Ujah, Elective caesarean sections at the Jos University Teaching Hospital. Tropical Journal of Obstetrics and Gynaecology, 2005. 22(1): p. 39-41.

21.Mutihir, J. T. and V. C. Pam, Obstetric outcome of twin pregnancies in Jos, Nigeria. Niger J Clin Pract, 2007. 10(1): p. 15-8.

22.Wanyonyi, S., E. Sequeira, and T. Obura, Caesarian section rates and perinatal outcome at the Aga Khan University Hospital, Nairobi. East African medical journal, 2006. 83(12): p. 651-658.

23.Melchor J.C, B. G., Ruiz R. Corcostegui B, Aranguren G, Mode of delivery of twins. An 11 years review (1980-1990) Journal of Obstetrics and Gynecology 1992. 12(4): p. 219-222.

24.ACOG Practice Bulletin \#56: Multiple gestation: complicated twin, triplet, and high-order multifetal pregnancy. Obstet Gynecol, 2004. 104(4): p. 869-83.

25.Leung T.-Y., T. W.-H., Leung T.-N. et al., Effect of twin to- 
twin delivery interval on umbilical cord blood gas in the

second twins. BJOG: Intern. J. of Obstet. and Gynecol., 2002. 108: p. 63-67.

26.Stein, W., B. Misselwitz, and S. Schmidt, Twin-to-twin delivery time interval: influencing factors and effect on short-term outcome of the second twin. Acta Obstet Gynecol Scand, 2008. 87(3): p. 346-53.

27.Schmitz, T., et al., Neonatal outcomes of twin pregnancy according to the planned mode of delivery. Obstet Gynecol, 2008. 111(3): p. 695-703.

\section{Tables}

Table.1; Demographic characteristics of the studied women by hospitals.

\begin{tabular}{|c|c|c|c|c|c|}
\hline \multirow[t]{3}{*}{ Maternal characteristics. } & \multicolumn{5}{|c|}{ Hospitals. } \\
\hline & $\mathrm{MNH}$ & Temeke & $\mathrm{M} / \mathrm{mala}$ & Amana & Total \\
\hline & $\mathrm{N}=195(\%)$ & $\mathrm{N}=227(\%)$ & $\mathrm{N}=129(\%)$ & $\mathrm{N}=115(\%)$ & $\mathrm{N}=666(\%)$ \\
\hline \multicolumn{6}{|l|}{ Age in years } \\
\hline$<20$ & $21(10.8)$ & $25(11.0)$ & $13(10.1)$ & $9(7.8)$ & $68(10.2)$ \\
\hline $20-34$ & 137(70.3) & $178(78.4)$ & $99(76.7)$ & $93(80.90$ & $507(76.1)$ \\
\hline$\geq 35$ & $37(18.9)$ & $24(10.6)$ & $17(13.2)$ & $13(11.3)$ & $91(13.7)$ \\
\hline \multicolumn{6}{|l|}{ Education level } \\
\hline No formal & 26(13.3) & $6(2.6)$ & $23(17.8)$ & 18(15.7) & $73(10.9)$ \\
\hline Primary & $65(33.3)$ & $78(34.4)$ & $41(31.8)$ & $34(29.6)$ & $218(32.7)$ \\
\hline Secondary & $90(46.2)$ & $130(57.3)$ & $55(42.6)$ & $62(53.9)$ & $337(50.6)$ \\
\hline College & $14(7.20$ & $13(5.7)$ & $10(7.8)$ & $1(0.8)$ & $38(5.7)$ \\
\hline \multicolumn{6}{|l|}{ Marital status } \\
\hline Single & $22(11.3)$ & $24(10.6)$ & $20(15.5)$ & $10(8.7)$ & $76(11.4)$ \\
\hline Married/cohabiting & 173(88.7) & 201(88.6) & 108(83.7) & 105(91.3) & $587(88.1)$ \\
\hline Divorced & 0 & $2(0.9)$ & $1(0.8)$ & 0 & $3(0.5)$ \\
\hline \multicolumn{6}{|l|}{ Parity } \\
\hline 1 & $44(22.6)$ & 43(18.9) & $31(24.0)$ & $21(18.3)$ & 139(20.9) \\
\hline 2 & $55(28.2)$ & $61(26.9)$ & $39(30.2)$ & $30(26.1)$ & $185(27.8)$ \\
\hline 3 & $48(24.6)$ & $60(15.4)$ & $30(23.3)$ & $32(27.8)$ & $170(25.5)$ \\
\hline$\geq 4$ & $48(24.6)$ & $63(27.8)$ & $29(22.5)$ & $32(27.8)$ & $172(25.8)$ \\
\hline \multicolumn{6}{|l|}{ Gestation age in weeks } \\
\hline 28- 37 & $89(45.6)$ & $107(47.1)$ & $57(44.2)$ & $58(50.4)$ & $311(46.7)$ \\
\hline$\geq 37$ & $106(54.4)$ & $120(52.9)$ & $72(55.8)$ & $57(49.6)$ & $355(53.3)$ \\
\hline
\end{tabular}


Table 2; Mode of delivery of twins at the four hospitals

\begin{tabular}{|c|c|c|c|c|c|}
\hline \multirow[t]{2}{*}{ Characteristics } & \multicolumn{5}{|c|}{ Hospitals } \\
\hline & MNH & Temeke & $\mathrm{M} / \mathrm{mala}$ & Amana & Total \\
\hline \multicolumn{6}{|l|}{ Mode of delivery } \\
\hline & $\mathrm{N}=195(\%)$ & $\mathrm{N}=227(\%)$ & $\mathrm{N}=129(\%)$ & $\mathrm{N}=115(\%)$ & $\mathrm{N}=666(\%)$ \\
\hline VD & $94(48.2)$ & $210(92.5)$ & $107(82.9)$ & $104(90.5)$ & $515(77.3)$ \\
\hline CS & $98(50.3)$ & $9(4.0)$ & $18(14.0)$ & $9(7.8)$ & $134(20.1)$ \\
\hline Combined & $3(1.5)$ & $8(3.5)$ & $4(3.1)$ & $2(1.7)$ & $17(2.6)$ \\
\hline \multicolumn{6}{|c|}{ Type of caesarian section } \\
\hline & $\mathrm{N}=101(\%)$ & $\mathrm{N}=17(\%)$ & $\mathrm{N}=22(\%)$ & $\mathrm{N}=11(\%)$ & $\mathrm{N}=151(\%)$ \\
\hline Elective & $26(25.7)$ & $5(29.4)$ & $4(18.2)$ & $1(9.1)$ & $36(23.8)$ \\
\hline Emergency & $75(74.3)$ & $12(70.6)$ & 18(81.8) & $10(90.9)$ & $115(76.2)$ \\
\hline
\end{tabular}

VD-Vaginal delivery CS- Caesarian section

Table 3a; Neonatal outcomes at birth in relation to the mode of delivery

\begin{tabular}{llllll}
\hline Outcomes & \multicolumn{2}{l}{ Vaginal delivery } & \multicolumn{2}{l}{ Caesarian section } & Total \\
\hline & Twins 1 & Twins 2 & Twins 1 & Twins 2 & \\
& $\mathrm{N}=524(\%)$ & $\mathrm{N}=523(\%)$ & $\mathrm{N}=142(\%)$ & $\mathrm{N}=143(\%)$ & $\mathrm{N}=1332(\%)$ \\
\cline { 2 - 6 } & & & & & \\
Alive & $498(95.1)$ & $486(93.0)$ & $133(97.7)$ & $135(94.4)$ & $1252(94.0)$ \\
FSB & $18(3.4)$ & $27(5.1)$ & $8(5.6)$ & $7(4.9)$ & $60(4.5)$ \\
MSB & $8(1.5)$ & $10(1.9)$ & $1(0.7)$ & $1(0.7)$ & $20(1.5)$ \\
\hline
\end{tabular}

FSB-Fresh stillbirth MSB-Macerated stillbirth 
Table 3b; Neonatal outcomes according to the modes of delivery

\begin{tabular}{|c|c|c|c|c|c|c|}
\hline \multicolumn{4}{|c|}{ Neonatal outcomes TWIN 1} & \multicolumn{3}{|l|}{ TWIN 2} \\
\hline \multirow[t]{2}{*}{ APGAR score } & VD & CS & \multicolumn{2}{|c|}{ p-value VD } & CS & p-value \\
\hline & $\mathrm{N}=524(\%$ & $\mathrm{N}=142(\%)$ & & $\mathrm{N}=523(\%)$ & $\mathrm{N}=143(\%)$ & \\
\hline MSB & $8(1.5)$ & $1(0.7)$ & & $10(1.9)$ & $1(0.7)$ & \\
\hline FSB & $18(3.4)$ & $8(5.7)$ & 0.20 & $27(5.2)$ & $7(4.9)$ & 0.48 \\
\hline AS $<7$ at $1 \mathrm{~min}$ & $76(14.5)$ & $5(3.5)$ & & $116(22.2)$ & $11(7.7)$ & \\
\hline $\mathrm{AS} \geq 7$ at $1 \mathrm{~min}$ & $422(80.5)$ & $128(90.1)$ & 0.003 & $370(70.7)$ & $124(86.7)$ & 0.001 \\
\hline AS $<7$ at $5 \mathrm{~min}$ & $27(5.2)$ & $1(0.7)$ & & $41(7.8)$ & $6(4.2)$ & \\
\hline $\mathrm{AS} \geq 7$ at $5 \mathrm{~min}$ & $471(89.9)$ & $132(93.0)$ & 0.099 & $445(85.1)$ & $129(90.2)$ & 0.135 \\
\hline
\end{tabular}

Key; AS- APGAR score, FSB-Fresh stillbirth, MSB-Macerated stillbirths

Table 4; Neonatal outcomes of second twins in relation to inter twin vaginal delivery time interval. 


\begin{tabular}{llll}
\hline Outcomes & \multicolumn{3}{c}{ Time interval in minutes p-value } \\
& $<30$ & $\geq 30$ & \\
& & & \\
& $\mathrm{~N}=467(\%)$ & $\mathrm{N}=56(\%)$ & \\
MSB & $6(1.3)$ & $4(7.1)$ & \\
FSB & $19(4.1)$ & $8(14.3)$ & 0.44 \\
AS $<7$ at $1 \min 72(15.4)$ & $27(48.2)$ & \\
AS $\geq 7$ at $1 \min 370(79.2)$ & $17(30.4)$ & $<0.0001$ \\
AS $<7$ at $5 \min 39(8.4)$ & $24(42.9)$ & \\
AS $\geq 7$ at $5 \min 403(86.3)$ & $20(35.7)$ & $<0.0001$ \\
\hline
\end{tabular}

Key; AS-APGAR score, MSB-Macerated stillbirth FSB-Fresh stillbirth

Table 5: Perinatal outcomes and perinatal mortality rate

\begin{tabular}{|c|c|c|c|}
\hline Outcomes & \multicolumn{3}{|c|}{$\begin{array}{l}\text { Twin } 1 \text { Twin } 2 \text { Total } \\
{ }^{*} \mathrm{~N}=606{ }^{*} \mathrm{~N}=610^{*} \mathrm{~N}=1216\end{array}$} \\
\hline Stillbirth & 35 & 45 & 80 \\
\hline Early neonatal death & 41 & 67 & 108 \\
\hline Alive and well & 449 & 405 & 846 \\
\hline Alive admitted neonatal units & 89 & 93 & 182 \\
\hline Perinatal mortality per 1000 & 125 & 184 & 155 \\
\hline
\end{tabular}

*Information of 60 first twins and 56 second twins about the neonatal status on day seven was missing.

Table 6; Causes of twins neonatal admissions by day seven. 


\begin{tabular}{lllll}
\hline Reasons & \multicolumn{2}{l}{ Twin 1 } & Percentage Twin 2 & Percentage \\
& \multicolumn{2}{l}{ N=105* } & \multicolumn{2}{l}{ N=116* } \\
\hline Prematurity & 51 & 48.6 & 62 & 53.4 \\
Birth asphyxia & 19 & 18.1 & 16 & 13.8 \\
RDS & 16 & 15.2 & 23 & 19.8 \\
Neonatal jaundice & 7 & 13.7 & 3 & 2.6 \\
Neonatal sepsis & 4 & 3.8 & 8 & 6.9 \\
Pneumonia & 7 & 6.7 & 4 & 3.4 \\
Fracture of the humerus & 1 & 0.9 & 0 & \\
\hline
\end{tabular}

Key; ${ }^{*}$ More than one reason for admission occurred in some neonates, RDS-Respiratory distress syndrome. 